\title{
CUIDADO PRESTADO PELA EQUIPE DE SAÚDE ÀS FAMÍLIAS DE CRIANÇAS QUE SOFRERAM ASFIXIA PERINATAL GRAVE
}

\section{CARE PROVIDED BYTHE HEALTH TEAM TO FAMILIES OF CHILDREN WHO SUFFERED ASPHYXIA PERINATAL RECORD}

\section{RESUMO}

Objetivo: Conhecer os cuidados prestados pela equipe de saúde às famílias de crianças que sofreram asfixia perinatal grave. Metodologia: Exploratória, descritiva, qualitativa. Realizada numa cidade do sul do Rio Grande do Sul, tendo como participantes, quatorze profissionais da equipe de saúde da unidade de terapia intensiva neonatal e da pediatria de um hospital universitário de abril a maio do ano de 2011. Foram utilizadas entrevistas semiestruturadas e a Análise Temática de Minayo. Resultados: Revelam que na transmissão do diagnóstico de Asfixia perinatal grave, falta um feedback positivo, pois os profissionais informam o diagnóstico sem que as famílias compreendam o seu significado. Conclusão: Os cuidados básicos são fornecidos, porém o seguimento necessita de um serviço que consiga abranger este cuidado a família de forma holística e integral, com equipes multidisciplinares para que sejam alcançadas perspectivas de uma maior autonomia da família para o cuidado à criança.

Palavras-Chave: Asfixia neonatal; Cuidado da criança; Criança; Família; Crianças com deficiência; Paralisia cerebral.

\section{ABSTRACT}

Objective: To know the care provided by the health team to the families of children who have suffered severe perinatal asphyxia. Methodology: Exploratory, descriptive, qualitative. Held in a city in southern Rio Grande do Sul, with the participants fourteen professional health team from the neonatal intensive care unit and pediatrics of a university hospital from April to May of 2011. Semi-structured interviews were used and the Thematic Analysis of Minayo. Results: They reveal that in transmitting the diagnosis of severe perinatal asphyxia, lack a positive feedback, as professionals inform the diagnosis without that families understand their meaning. Conclusion: Basic care is provided, but the follow-up needs a service that can cover this care family in a holistic and comprehensive manner, with multidisciplinary teams to prospects for increased autonomy for family child care are met.

KeyWords: Asphyxia neonatorum; Child Care; Child; Family; Disabled Children; Cerebral Palsy.
Elaine de Oliveira Vieira Caneco Correio Enfermeira. Graduação em Formação Pedagógica para Enfermeiros pelo Instituto Federal Sudeste de Minas Gerais.

\section{Viviane Marten Milbrath Correio}

Universidade Federal de Pelotas

Doutora em Enfermagem. Professora Adjunta do curso de graduação em Enfermagem e do Programa de Pós- Graduação em Enfermagem (PPGEnf) da Universidade Federal de Pelotas (UFPel). Enfermeira.

Vera Lucia Freitag Correio

Doutoranda em Enfermagem pela Universidade Federal do Rio Grande do Sul (UFRGS). Mestra em Ciências. Especialista em Gestão de Organização Pública em Saúde. Enfermeira.

Contato principal para correspondência.

Simone Coelho Amestoy Correio

Universidade Federal da Bahia

Doutora em Enfermagem. Professora Adjunta da

Universidade Federal da Bahia. Enfermeira. 
Introdução

Considera-se o cuidado um elemento que compreende o ser humano, estando agregado a sua existência. Nessa conjuntura, cuidar consiste em dispor esforços transpessoais de um ser humano para outro ser, buscando proteger, promover e preservar a humanidade, ajudando os seres humanos a encontrarem significados na sua própria existência. 1

O momento de cuidar é concretizado de modo pleno quando se estabelece um elo de confiança entre ser cuidado e ser que cuida, sendo que em princípio, para despertar essa confiança, o cuidador deverá demonstrar responsabilidade competência, respeito e sensibilidade.2

Sob essa perspectiva, propõe-se refletir sobre o contexto que envolve o diálogo entre a equipe de saúde e a família da criança que sofreu uma asfixia perinatal grave. Considerou-se nesse estudo Asfixia Perinatal Grave recém-nascido com índice de APGAR (teste de desenvolvimento) menor ou igual a seis no quinto minuto.3 Entretanto, verifica-se uma maior incidência de paralisia cerebral em recém-nascidos com este índice inferior a três no quinto minuto. OAPGAR baixo no primeiro minuto de vida deve ser usado como um indicador de asfixia prévia e não como um fator que predisponha a um dano neurológico, porém se a asfixia produzir um APGAR baixo no quinto minuto, isso indica quase com certeza, que o recém-nascido apresentará lesões neurológicas. 4

Neste sentido, pode-se observar que um APGAR baixo é um indicativo de lesão neurológica, não a confirmação de tal sequela, a incerteza perpassa também o prognóstico em relação ao processo de crescimento e desenvolvimento da criança. As incertezas em relação à sequela neurológica e ao prognóstico da criança representam questões que dificultam o diálogo entre o profissional da saúde e a família. Visto que é complexo explicar um diagnóstico e um prognóstico incerto para a família e, da mesma forma, a família acaba tendo dificuldade em compreender tal situação.

Estudos têm mostrado que, em muitos casos de crianças que nascem com necessidades especiais, os pais não conseguem compreender o que foi transmitido pela equipe de saúde em função da linguagem utilizada pelo profissional de saúde. 5 Nessa lógica, destaca-se a atuação do profissional de enfermagem prestar este cuidado aos pais, que neste momento necessitam de apoio, compreensão e atenção. Existe uma lacuna entre informações fornecidas pela equipe de saúde e a compreensão da família, onde os pais tem dificuldade em entender a linguagem técnica utilizadas pelos profissionais, acrescido ao receio de questionar o que não haviam entendido nas informações fornecidas. 6 Esta lacuna, leva as famílias a um desconhecimento do diagnóstico da criança, a qual prejudica o processo dialógico do cuidado.

Cuidar de famílias que experienciam o nascimento de um filho que sofreu asfixia perinatal grave desenvolvendo paralisia cerebral é fundamental para fortalecê-las no enfrentamento das adversidades provocadas pela condição do filho e para a manutenção do funcionamento e interações familiares saudáveis7. Os pais ao receberem a notícia do nascimento de um filho com Paralisia Cerebral, que pode desenvolver necessidades especiais, enfrentam períodos de dificuldade, principalmente no que diz respeito às interações com o filho, pois emocionalmente ficam muito abalados8.

Nesse contexto, os profissionais de saúde poderão auxiliar na redução desse momento de instabilidade emocional dos pais, ajudando na formação do vínculo, explicando os procedimentos, tratamentos, condições de saúde da criança e os cuidados a serem dispensados ao filho8. A aproximação entre a equipe de saúde e a família é importante para os pais sentirem-se apoiados e à vontade para esclarecerem dúvidas, o que diminui a ansiedade e impede que fiquem sobrecarregados pela situação do recém-nascido9.

Nesse sentido, é necessário que, além de obter informações diagnósticas claras, os pais sejam orientados quanto aos cuidados e procedimentos básicos em relação à criança e informados sobre as oportunidades educacionais, os recursos de assistência intelectual, emocional e financeira, bem como dos serviços de reabilitação disponíveis na comunidade para crianças com problemas semelhantes ao de seu filho.

A partir do exposto, este estudo teve como objetivo: conhecer os cuidados prestados pela equipe de saúde às famílias de crianças que sofreram asfixia perinatal grave.

\section{Metodologia}

Trata-se de um estudo descritivo e exploratório a luz de uma abordagem qualitativa, realizada no período de abril a maio do ano de 2011, na Unidade de Terapia Intensiva Neonatal (UTIN) e na Pediatria de um Hospital Universitário de médio porte, localizado em uma cidade da região sul do estado do Rio Grande do Sul (RS)

Participaram do estudo cinco enfermeiros, cinco médicos pediatras, quatro técnicos de enfermagem, perfazendo um total de quatorze participante, sendo dez do sexo feminino e três masculinos. Em média os participantes tinham 47 anos. Os médicos e enfermeiros são todos pós-graduados à nível de especialização. Os participantes foram identificados por pseudônimos de E1...E5 para enfermeiro, M1...M5 para médico pediatra e TE1...TE4 para técnico de enfermagem respectivamente conforme a ordem da entrevista. A seleção dos participantes foi feita por convite, sendo selecionados todos os profissionais que se mostraram interessados em participar da pesquisa, e que estavam trabalhando no setor no mínimo há um ano, e, portanto familiarizado e integrado com o mesmo; e que permitiram a gravação da entrevista e divulgação dos resultados encontrados em artigos e revistas científicas. Os participantes assinaram o Termo de Consentimento Livre e Esclarecido. Preservou-se a privacidade dos depoentes respeitando o seu anonimato.

As informações foram coletadas por meio de entrevistas semiestruturadas, dentre as quais os pesquisadores efetuaram os seguintes questionamentos: Quais as orientações fornecidas à família acerca do diagnóstico de Asfixia Perinatal Grave? Você acha importante serem fornecidas informações à família acerca dos direitos destas crianças e de suas famílias?

As entrevistas foram realizadas em uma sala reservada, no próprio hospital, gravadas e transcritas logo após a sua realização. Para interpretação das informações adotou-se a análise temática, proposta de Minayo10, emergindo assim, uma categoria tematica: Cuidados prestados pelos profissionais de saúde à família da criança que sofreu uma asfixia perinatal grave.

Em atenção às normas da pesquisa, envolvendo os seres humanos, o projeto foi submetido ao Comitê de Ética em Pesquisa da Santa Casa de Misericórdia de Pelotas para avaliação, sendo aprovado sob o número 139/2011.

\section{Resultados e Discussão}

A partir da interpretação das informações, emergiu uma unidade temática: Cuidados prestados pelos profissionais de saúde à família da criança que sofreu uma asfixia perinatal grave.

Cuidados prestados pelos profissionais de saúde à família da criança que sofreu uma Asfixia Perinatal Grave.

Ao se realizar o cuidado do outro se pratica além de uma ação técnica uma ação sensível, que envolve o contato entre humanos, através do toque do olhar, do ouvir, do olfato, da fala. Esta acão envolve a sensibilidade própria do sentidos e também a liberdade, a subjetividade, a intuição e a comunicação11. 0 cuidado é considerado uma condição fundamental para a sobrevivência do ser humano12.

Sob essa perspectiva de cuidado salienta-se como uma das funções dos profissionais de saúde o ato de auxiliar os pais da criança que sofreu asfixia perinatal grave a compreenderem a situação do recém-nascido o mais precocemente possível, tendo a sensibilidade de perceber o momento em que os pais estejam abertos para ouvir, respeitando seu período de sofrimento e negação. Os profissionais da saúde necessitam transmitirem as informações diagnósticas de acordo com a capacidade de compreensão e aceitação dos pais, sem utilizar linguagem técnica, incompreensíveis que acabam gerando um distanciamento entre a família e profissional5-6. É fundamental que o profissional da saúde compreenda que o tornar-se família de uma criança com paralisia cerebral é um processo complexo, exigindo da equipe de saúde atuante preparo profissional, além dos aspectos éticos e estéticos do processo de cuidar dessa família13.

Ao dialogar com os participantes do estudo sobre as orientações de cuidado prestadas à família da criança, percebese que é salientada a importância da equipe multidisciplinar no cuidado a esta família, orientando e estimulando esta, a comemorar cada conquista, pois a criança é especial e única e terá o seu tempo para atingir as fases de desenvolvimento de acordo com seu potencial e o empoderamento que receba, como pode-se comprovar no depoimento a seguir:

[...] as orientações [...] é que a criança precisa ser acompanhada por uma equipe multidisciplinar. (M1).

[...] a primeira coisa que eu digo para eles é que cada dia é um dia, que as conquistas todas têm que ser comemoradas, [...] então a cada momento que eu tenho contato eu procuro ir dizendo alguma coisa, às vezes tu diz a 
mesma coisa várias vezes até a pessoa entender (M2)

[...] vai depender das sequelas, por exemplo, tu tens uma criança que fez um asfixia perinatal grave e ela fez uma insuficiência renal, ela vai receber orientações especificas em relação a cuidar o volume de urina, a cor da urina, o bebe tem que ser pesado frequentemente para ver se não está edemaciando, esse bebê tem que ter um acompanhamento com um nefrologista pediátrico, a primeira orientação pra qualquer situação é voltar ao ambulatório ou a UBS ou ao consultório do pediatra, se esse paciente a exemplo fez uma encefalopatia hipóxico isquêmica ele já deve sair do hospita com a programação de um neurologista para vê-lo ( M5)

A partir do exposto, percebe-se a importância de dar ênfase as orientações aos pais, respeitando suas potencialidades e fragilidades. A falta destas, relacionadas à prevenção a agravos que uma criança que sofreu asfixia perinatal grave possa desenvolver, deixa-a suscetível a apresentar quadros de pneumonia de repetição por exemplo. A orientação adequada auxilia e empodera a família a descobrir suas próprias forças e potencialidades, sabendo o que A orientação adequada auxilia e empodera a família a descobrir suas próprias forças e potencialidades, sabendo o que
fazer para prevenir este tipo de situação, além disso, o participante M2 traz em seu discurso algo muito importante que é valorização das conquistas diárias da criança, enfatizar para a família que essa criança é única e muito especial, que ela não deve ser comparada com as outras crianças, que ela só deve ser comparada consigo mesma, seus progressos diários devem ser comemorados, bem como a importância da família compreender o que o profissional está transmitindo, mesmo que este necessite ser dito muitas vezes.

Torna-se importante a abordagem da equipe de saúde no sentido de sensibilizar os pais, para que eles também se sintam cuidados e compreendam que para uma criança asfixiada, conseguir firmar a cabeça é uma vitória que deve se tão comemorada como dar o primeiro passinho, essa compreensão é fundamental para a sua adaptação à criança e para o processo de crescimento e desenvolvimento infantil. Nesse sentido, o profissional deve estar preparado para oferecer informações, estar aberto e atento às interações com vistas a direcioná-los quanto aos cuidados necessários, atentando para as conquistas da criança com necessidades especiais. Para isso, o profissional necessita de uma base teórica que Ihe forneça subsídios para orientar e dar apoio à família, dirimindo suas dúvidas e reduzindo suas incertezas quanto ao futuro de uma criança que durante toda a vida dependerá de cuidados especiais de alguém14.

Nos discursos interpretados dos participantes, percebe-se que as orientações são proferidas pontualmente à medida que vão aparecendo os problemas, nesse sentido é necessário a existência de locais apropriados para este seguimento, pois sabe-se que as alterações clínicas aparecerão, mas não se pode afirmar com certeza quais crianças desenvolverão tais e quais problemas e nem o momento em que serão acometidas por eles, nesse sentido 0 acompanhamento se faz imprescindível e essencial.

O participante M5 diz que a criança que sofreu asfixia perinatal grave pode desenvolver insuficiência renal. Neste sentido, a Oligúria (diurese inferior a $1 \mathrm{ml} / \mathrm{kg} / \mathrm{hora}$ ) ou anúria é comum no recém-nascido que sofreu de asfixia perinatal, pode ocorrer necrose tubular aguda ou desidratação, são causas de oligúria e merecem um diagnóstico diferencial, pois ocorrem com alguma frequência em recém-nascidos asfixiados 15. Assim torna-se essencial as orientações especificas em relação a cuidar o volume de urina, a cor da urina, estar atento ao peso do bebê, atenção para possível edema e te um acompanhamento com um nefrologista pediátrico.

Todas estas informações/orientacões e incertezas deixam os pais ansiosos, confusos, por isso a importância dos profissionais reconhecerem que a família por estar passando um momento difícil e delicado de suas vidas, não pode se sobrecarregada com informações, pois não conseguiria assimilar todas ao mesmo tempo, sendo necessário às vezes proferir a mesma informação mais de uma vez para que seja absorvida pela família e em linguagem compreensível pelos pais com cuidado e cuidando-os ao mesmo tempo.

No primeiro momento a gente fala que a criança é uma criança que nasceu grave e que a gente não sabe em que condições que vai sair, o que vai acontecer. [...] APGAR baixo tem grandes riscos de sequelas neurológicas [...] o cuidado, eu recomendo numa observação inicial, convulsão, movimentos diferentes, a sonolência, [...] podem ter convulsão devido à falta de oxigênio, prejudica os sistemas mais importantes, já explico ali, porque eles têm que estar cientes, tem que saber [...] (M3).

Por meio desse discurso, pressupõe-se que 0 cuidado preventivo será determinante para 0 desenvolvimento da criança e que como já vem sendo discutida, a família deve ser inserida neste cuidado, uma vez que é nela que se encontra a base de qualquer transformação, quanto mais informações sobre a condição da criança, formas de intervenção, tratamentos existentes e onde procurar acompanhamento, melhor será para o futuro da criança, que encontrará no cuidado conjunto de profissionais de saúde e família a melhor maneira de conviver com o contexto em busca da autonomia.

Neste sentido, torna-se importante o diálogo cuidador, pois não é algo simples, a busca do encontro cuidador mediado pelo diálogo é uma arte e não um poder a ser exercido. Trata-se de um exercício a ser realizado no cotidiano de nossa prática como profissionais de saúde, mas deve ser exercitado também como seres humanos. É um exercício contínuo de buscar a palavra adequada a ser utilizada com o outro no momento certo, o gesto apropriado, o respeito em relação ao meu ser como indivíduo histórico e em relação ao outro como um ser autêntico, como um ser-no-mundo no sentido mais literal e complexo da expressão16.

No discurso a seguir pode-se ver que apesar de ser dado muitas informações, a participante E2, diz que o período de internação é muito curto para ser a família completamente empoderada:

[...] 0 que a gente orienta a família é que essa é uma criança que vai precisar de estímulos [...], tem que ter cuidados maiores [...] E orientar a família a saber quais as consequências da asfixia perinatal [...], embora muitas vezes a criança tem uma boa desenvoltura, é uma caixinha de surpresas, então muita coisa pode mudar. [...] mas ela pode ter dificuldade, por exemplo, de alimentação, até na deglutição a dificuldade de movimento, de firmar, sentar, de caminhar, algumas coisas assim, atraso em falar, essas coisas podem ir se colocando, embora seja um período muito curto de internação e nem tudo é esclarecido, como deveria (E2).

Conforme este discurso é imprescindível que o profissional de saúde seja sensivel com os pais, pois é um momento delicado, estes, tem dificuldade em compreender como um bebê "aparentemente" sem nenhuma alteração pode ter paralisia cerebral, adentrando no processo de reorganização do modo de ser-no-mundo desta família para se adaptar ao novo ser e as demandas de cuidado que esse necessita. Percebe-se a importância da orientação em relação ao estímulo que a família deve dar à criança, bem como das implicações que podem acarretar a não estimulação precoce. A criança é comparada a uma caixinha de surpresas, verifica-se neste relato indícios da plasticidade neuronal, pois quando a criança é estimulada precocemente, seu desenvolvimento pode ser muito maior do que o imaginável.

A identificação e intervenção precoces são fundamentais para o prognóstico das crianças com distúrbios do desenvolvimento, pois é um processo que se inicia desde a vida intrauterina e abarca vários aspectos, como o crescimento físico, a maturação neurológica e a construção de habilidades relacionadas ao comportamento, às esferas cognitiva, social e afetiva da criança. Tem como produto tornar a criança competente para responder às suas necessidades e às do seu meio, considerando seu contexto de vida17.

No discurso a seguir se pode observar que os profissionais vão aos poucos informando aos pais, pois se o bebê está na UTI, o contato com a mãe é mais escasso. Mas se o alojamento é conjunto ou no momento da alta na UTI a mãe começa a perceber que o filho é diferente do esperado, e, a partir da percepção da mãe ou dos pais é que o profissional vai intervindo.

[...] falo sem usar muitos termos técnicos, pergunto se ela sabe que o bebê dela é diferente dos outros, que ele é mais quietinho, se ela percebeu isso, que ele é diferente, [...] mas não é a mesma coisa e no momento que o bebê está com ela é que ela vai enxergar que o bebê dela é diferente dos outros, normalmente começamos o assunto por ai, se ela reconhece, percebeu que o bebê não chora tanto, que é quietinho, tem dificuldade para sugar, e com essas informações assim é que eu consigo ver o quê que ela sabe, não costumo tocar na palavra asfixia porque acho que é um termo técnico que ela não entende, se eu vejo que ela já entendeu alguma coisa, eu procuro sempre, tentar explicar e com palavras simples (E3).

Verifica-se neste relato a importância da criação do vínculo, bem como a necessidade de se usar tato e sensibilidade para conseguir orientar a família, pois esta não dispõe do mesmo nível de saberes que um profissional. Mais uma vez, nota-se que o profissional enfermeiro é o que se encontra mais próximo à família, por isso a importância deste profissional dispor do cuidado à família, na medida em que este tem no conjunto de suas atribuições a prática de educação em saúde.

E importante que o profissional fique atento ao momento dos pais, observando qual a hora certa que possa esta intervindo, usando sensibilidade, cuidado, baseado em um diálogo acolhedor, humanizado, criando vínculo com a família para que esta possa ter uma referência nestes profissionais, uma rede de apoio

Outro ponto que surge nos discursos é a questão da criança diferente, pois ser diferente não significa ser anormal, 
quando as pessoas utilizam a palavra "normal", não percebem a carga histórica que esta palavra encerra, o padrão de normalidade é uma referência social e histórica. A paralisia cerebral é uma condição da criança, que exige cuidados especiais, isso não quer dizer que ela é anormal, por isso há necessidade de que os pais estejam bem orientados no sentido de tratar do filho sem preconceito que a sociedade impõe.

Uma criança que apresenta uma deficiência física ou mental não é um ser incapaz, apenas diferente. Médicos, pais, amigos, parentes, todos, sem dúvida, bem-intencionados, se encarregarão de convencer essas crianças, ou de ajudá-las a aprenderem, de que não são incapazes. Para ele é muito difícil evitar tal atitude, pois nossos próprios medos, ignorâncias, apreensões e preconceitos surgirão sob milhares de formas distintas, a maioria delas inconscientes18. É essencial que os profissionais e cuidadores de crianças com paralisia cerebral, policiem-se, a fim de assegurar que não estejam colaborando para o processo de incapacitação destes indivíduos. Ressalta o pesquisador que ninguém nasce incapaz, mas é fabricado pela própria sociedade.

Pode-se dizer que todos os seres humanos são diferentes, ninguém é igual a ninguém, todos tem alguma limitação e também potencialidades, assim a criança com paralisia cerebral também é única14. Desta forma, a família busca adaptar-se e reorganizar-se a um novo cotidiano para enfrentar a experiência de viver e conviver com o filho com necessidades especiais, tentando reconstruir sua identidade como grupo familiar. Essa situação envolve sentimento de vulnerabilidade e também um reajuste emocional que requer tempo. Por isso a importância do cuidado do profissional à esta família dando suporte neste momento de adaptação, o profissional deve compreender as fases de adaptação dos pais a nova situação.

0 profissional, em especial o enfermeiro, deve orientar estes pais sobre alimentação, troca de fralda, visitas ao pediatra e se colocar à disposição para que esta família sinta-se amparada e cuidada pela equipe de saúde, criando vínculo, para que estes não sintam-se intimidados em falar de suas fraquezas para assim serem orientados e sensibilizados quando ao cuidado do filho, como podemos ver no relato a seguir:

As orientações básicas, em primeiro lugar é saber cuidar do nenê, do jeito que ele é. Trocar, talvez ele não vá reclamar muito, então tem que saber, tem que estar atento, a maneira de alimentar, tem uma serie de técnicas de cuidados de manejo para alimentar (E4).

[...] são passadas assim, que vai ser uma criança especial, que vai ter mais cuidado, que vai ter que ir frequentemente a um pediatra, que vai ter que ficar atento, qualquer coisa diferente (TE1).

Crianças que sofreram a asfixia perinatal grave podem desenvolver a encefalopatia hipóxico isquêmica, que atualmente é tida como uma condição da criança ser/estar no mundo, e não mais como uma doença, a família deve se adaptar a esta condição para poder cuidar desta criança como ela é, respeitando seus limites e explorando suas potencialidades14. Dentro deste contexto os profissionais de saúde têm fundamental importância, a partir do momento que identificam as dificuldades destas famílias e permitem a elas um acompanhamento e orientação adequada no momento preciso.

Outro ponto que merece destaque é que alguns profissionais percebem que os pais não são orientados para realizar o cuidado à criança durante a internação do recém-nascido. Segundo os depoimentos as informações e orientações repassadas para os pais ocorrem de acordo com a vivência de cada profissional, e a necessidade que estes percebem de inserir as mães no cuidado, o que necessariamente não parte de todos os profissionais, por não existir uma forma padronizada, protocolada, para que isto aconteça, como podemos ver no discurso que segue:

[...] orientações de cuidado, posso te dizer que são quase nulas, acaba que tu não ensina aquela pessoa a ter autonomia para depois ela assumir aquela criança, [...] o que acontece , não é a rotina, as vezes tem algumas pessoas que trabalham aqui que já deixam o pai fazer alguma coisa [...], Eu mesmo penso assim pelo menos, você deixa dar 0 leite, para ela sair daqui, se é uma criança que por exemplo vai ficar com traqueostomia, os pais depois em casa vão ter que aspirar, poderia ser feito isso aqui, mas não é, não sei se na pediatria eles introduzem o pai e a mãe a fazer isso ai mas aqui não (TE2)

O discurso salienta a importância de o profissional estimular o cuidado da família à criança. A presença da família mostra-se imprescindível para a criança, o toque, o som da voz, a energia passada pela presença dos pais é de fundamental importância na recuperação. O profissional de saúde por sua vez, poderá estar orientando e facilitando este momento dos pais com o filho no período de internação.

O recém-nascido que apresenta agravos que necessita de assistência especializada, contudo, além de um ambiente físico adequado exige preparo técnico-científico da equipe de saúde para que possa atuar no plano biológico e nas atividades que minimizem sequelas e promovam o crescimento e o desenvolvimento saudável da criança19.

Atualmente enfatiza-se a importância do toque em situações psicoterapêuticas, sendo a pele e 0 ato de tocar aspectos importantes para a saúde física e mental. A necessidade do toque é existencial, e para os recém-nascidos doentes essa prática é bem discutida entre os profissionais da neonatologia, ao defenderem que o sentido do tato é desenvolvido ainda no início da vida fetal. Como em prematuros, a pele é extremamente sensível e frágil o toque deve ser feito com muito cuidado para não se tornar estressante.

Os profissionais de saúde devem orientar aos pais a tocarem seus filhos, porém de modo leve, sem estimulações excessivas, evitando uma possível desorganização física. Em bebês prematuros estáveis o toque tem mostrado benefícios, ajudando inclusive no ganho de peso mais rápido20.

[...] A gente encaminha para a parte psicológica da instituição e auxilia da maneira mais simples, até mesmo a crença, a parte religiosa e espiritual. [...] toda atividade necessária que a gente faz, até mesmo como a gente age com a criança a gente já vai passando, alimentação, muitas vezes na parte de exercício, da parte motora a gente também auxilia um pouco. A gente não vai direto dizer que tem que ser assim, eles acompanha o profissional que está cuidando e de repente temos que auxiliar, porque a mãe fica deprimida, chocada com a situação, até mesmo a gente fica, por que vê que ela tinha tudo pra nascer bem e nascer perfeita, e ai acontece uma situação dessas (TE3).

O discurso acima nos faz refletir sobre o cuidado ao ser biopsicosocioespiritual, retoma ainda as fases pela qual a família passa diante uma doença como explicitado anteriormente, onde devem ser respeitadas suas crenças, valores, sua forma de entender e a partir disso ir repensando a forma de cuidar esta família na sua integralidade. A interdisciplinaridade e a busca da prática da integralidade no ambiente de trabalho, quando estabelecidas, formam um elo acolhedor, onde a família sente-se segura em relação às informações recebidas bem como das lacunas existentes na adaptação ao cuidado deste novo ser21.

Após a alta hospitalar, a continuidade do cuidado à saúde das crianças em domicílio é de fundamental importância, a partir do momento que ajuda na diminuição dos índices de morbidade dessas crianças. É primordial que os pais sejam incentivados pelos profissionais da equipe de saúde a participar ativamente dos cuidados prestados aos seus filhos, devendo ser inicialmente orientados e acompanhados pela equipe, pois é comum a família relatar que tem medo de não saber cuidar corretamente da criança, pois os veem como serem muito frágeis, necessitados de cuidados especiais que elas não saberiam oferecer. Sendo assim, 0 incentivo e a ajuda prática sobre o cuidar facilitam 0 aprendizado e contribuem para a diminuição da ansiedade dos pais, fortalecendo mais ainda o vínculo pais-filho21.

Neste sentido, percebe-se a importância do profissional de saúde reconhecer a importância da presença da família nos cuidados à criança e valorizá-la no contexto do cuidado. Mediante esta necessidade de orientar a família, principalmente no momento da alta, os participantes foram interrogados se havia algumas recomendações e ou aconselhamento especial para estas famílias, a partir do momento que recebiam a liberação para irem para casa, ao que se obteve como resposta as seguintes considerações.

Ah, sim, com certeza, da estimulação precoce quanto mais cedo forem orientados, e também a orientação de um bom acompanhamento pediátrico no primeiro ano de vida. [...] o pediatra vai acabar encaminhando, para um fisioterapeuta, um fono, otorrino, ver se tem deficiência acústica ou não, [...] (M2)

Sim, [...] a orientação mais importante é a convulsão quando nos temos a criança asfixiada que convulsionou em principio ela sai com anticonvulsivante e a gente tem que preocupar com uma sequela maior neurológica [...] (M3)

[...] Nós sempre trabalhamos em conjunto com a assistência social e o serviço de psicologia, o serviço social nos apóia muito, então além das dúvidas que a mãe e o pai têm, além do que a gente pode esclarecer de dúvidas 0 
serviço social ajuda bastante, consegue muitas vezes APAE, e faz com que o serviço social do município saiba que essa criança é diferenciada, que pode precisar de mais consultas, neurologista, vai precisar de tomografia, mais que outras, normalmente (E1).

As mães já são treinadas antes de dar alta, para dar o leite, para como trocar a fralda, olhar o tônus da pele, olhar a parte respiratória, tudo isso (TE1)

[...] a gente (enfermagem) ajuda as mães, para quando elas forem para casa já estarem treinadas. A gente explica que a criança vai ser um pouco mais lenta, que ela não vai ser como os outros [...], que ela tem que observar e a qualque alteração procurar ajuda (TE4).

As orientações gerais de cuidado e manejo com a criança que sofreu um insulto grave, como a alimentação, medicamentos, doses e horários são passadas aos poucos aos pais, tanto na UTIN como na pediatria, isto pode ser observado nas colocações dos profissionais de saúde, porém, as orientações de um cuidado mais voltado ao desenvolvimento e acompanhamento da criança não são passadas de uma maneira formal, a inexistência de um protocolo oficial para a alta, que direcione o cuidado pautado nos problemas da criança, com orientações de retornos médicos, encaminhamentos para instituições especializadas, orientações sobre o desenvolvimento neuromotor e cognitivo e a importância do acompanhamento são um entrave para estas famílias.

Pode-se observar nos discursos, há uma carga de informações repassadas aos pais, principalmente se esta criança teve convulsão ainda no ambiente hospital. No entanto as informações quanto ao desenvolvimento psicomoto ainda são frágeis, pois depende muito do tempo de desenvolvimento da criança para ir se observando as sequelas.

Estudos tem comprovado que a intervenção precoce tem-se obtido excelentes resultados no desenvolvimento cognitivo de crianças com paralisia cerebral, obtendo-se lucros no desenvolvimento psicomotor. Salientam ainda que os poucos estudos existentes sobre intervenção precoce em crianças em desenvolvimento tem sido desenvolvidos por meio de programas de orientações à família22.

Neste contexto, cuidar de famílias que tem experiência de viver com um filho que sofreu asfixia perinatal grave é fundamental para fortalecê-las no enfrentamento das adversidades provocadas pela condição do filho e para a manutenção do funcionamento e interações familiares saudáveis5. Neste sentido, os profissionais necessitam esta capacitados para cuidar da família promovendo seu fortalecimento, a fim de que esta se mantenha coerente para 0 desempenho de suas funções no cuidado do filho.

Os atos realizados no cuidado variam, de acordo com as condições em que ocorrem as situações e com o tipo de relacionamento estabelecido, por isso a importância do vinculo entre profissional e familia da criança. Existem tipos diferentes ou maneiras distintas de cuidar, que variam de intensidade. A autora afirma ainda que a maneira de cuidar vai depender da situação, e na forma como nos envolvemos com ela e com a pessoa, motivo de atenção do cuidado23. É necessário novos conhecimentos para evolução na maneira de agir em saúde, mudanças que resultaram em positivas $e$ abrangentes formas de cuidar e de construir o cuidado na perspectiva holística, integral e humanizada24.

\section{Conclusão}

Ao buscar conhecer os cuidados prestados pela equipe de saúde às famílias, de crianças que sofreram uma asfixia perinatal grave, utilizou-se um olhar sobre alguns dos aspectos do cuidado, o que permitiu um entendimento sobre a forma como a equipe de saúde anuncia o diagnóstico da asfixia perinatal à família, bem como, as orientações para o cuidado ofertado a estas famílias.

Em relação aos cuidados à família de uma criança que sofreu uma asfixia perinatal grave, constatou-se que cuidados básicos são passados à família, porém há lacunas, onde verifica-se a necessidade de que as crianças sejam acompanhadas em um local apropriado para o seguimento, pois de acordo com o extraído dos discursos dos profissionais de saúde, algumas informações a cerca do desenvolvimento devem ser pontuais, a mediada em que surgem as dificuldades e os problemas.
Verifica-se também a necessidade da criação de um protocolo de alta, já que este possibilitaria aos profissionais atuarem de forma consciente das necessidades da família e da criança. Salienta-se que é responsabilidade dos profissionais de saúde orientar e informar a família sobre o desenvolvimento da criança e sobre a estimulação precoce, além da formação de vínculo como fator essencial para este desenvolvimento, tendo sensibilidade em saber que a família também precisa ser cuidada.

Referencias Bibliográficas

1. Waldow VR. Cuidar: expressão humanizadora da enfermagem. Editora: Vozes Limitada; 2012.

2. Waldow VR, Rosália FB. "Cuidar e humanizar: relações e significados. Acta Paul. Enferm. $2011 ; 24(3): 414-8$

3. Sociedade Brasileira de Pediatria (SBP) Disponível em:<http://www.sbp.com.br> Acessado em: 22 maio 2015

4. Campos NG. Prevalência de asfixia perinatal e fatores associados em Fortaleza-Ceará / Nataly Gurgel Campos. Fortaleza, 2010. 91 p. Dissertação (Mestrado Acadêmico em Saúde Pública) - Universidade Estadual do Ceará, Centro de Ciências da Saúde, 2010.

5. Dantas MAS, Collet N, Moura FM, Torquato IMB. Impacto do diagnóstico de paralisia cerebral para a família. Texto Contexto Enferm. 2010;19(2):229-37.

6. Milbrath VM, Siqueira HCH, Motta MGC, Amestoy SC. Comunicação entre a equipe de saúde e a família da criança com asfixia perinatal grave. Texto Contexto Enferm. 2011;20(4):72634.

7. Barbosa MA, Balieiro MGF, Pettengrill MAM. Cuidado centrado na família no contexto da criança com deficiência e sua família: uma análise reflexiva. Texto Contexto Enferm. Florianópolis. 2012;21(1):194-9.

8. Milbrath VM, Soares DC, Amestoy SC, Cecagno D, Siqueira HCH. Mães vivenciando o diagnóstico da paralisia cerebral em seus filhos. Rev. Gaúch. Enferm. 2009;30(3):437-44

9. Barbosa MAM, Balieiro MMFG, Pettengrill MAM. Cuidado centrado na família no contexto da criança com deficiência e sua família: uma análise reflexiva. Texto Contexto Enferm. 2012;21(1):194-199.

10. Minayo MCS. O desafio do conhecimento: pesquisa qualitativa em saúde. $8^{a}$ ed. São Paulo: Hucitec; 2012.

11. Hoher SP; Wagner, ADL. A transmissão do diagnóstico e de orientações a pais de crianças com necessidades especiais: a questão da formação profissional. Estud. Psicol. Campinas. 2012;23(2):113-25.

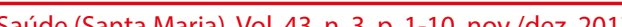


12. Waldow VR. As peculiaridades e contradições do cuidar. In: . O cuidado na saúde: as relações entre o eu, o outro e o cosmos. Petrópolis, RJ: Vozes; 2014. P.130- 58.

13. Milbrath VM; Siqueira HH; Motta MGC; Amestoy SC. Família da criança com paralisia cerebral: percepção sobre as orientações da equipe de saúde. Texto contexto - enferm. [online]. 2012;21(4):921-8.

14. Godimik M, Carvalho ZMF. Sentimentos das mães de criança com paralisia cerebral. Esc. Anna Nery. 2012;16(1):11-6.

15. Procianoy RS, Silveira RC. Síndrome hipóxico-isquêmica. J. Pediatr. 2001;77(Supl 1):63-70.

16. Milbrath VM. Criança/adolescente com paralisia cerebral: compreensões do seu modo de ser no mundo. 2013. 179f. Tese (Doutorado em Enfermagem) Universidade Federal do Rio Grande do Sul, Porto Alegre, 2013.

17. Sigolo ARL, Aiello ALR. Análise de instrumentos para triagem do esenvolvimento infantil. Paidéia. Ribeirão Preto. 2011;21(48):51-60.

18. Buscáglia LF. Os deficientes e seus pais: Um desafio ao aconselhamento. (Tradução Raquel Mendes). $5^{a}$ edição; Rio de Janeiro; Record; 2006.

19. Tavares AS, Queiroz MVO, Jorge MSB. Atenção e Cuidado à Família do Recém-Nascido em Unidade Neonatal: Perspectivas da Equipe de Saúde. Cienc. cuid. saude. 2006;5(2):193-203.

20. Perencin CC, Ribeiro CA. Tocando o prematuro: significado para auxiliares e técnicas de enfermagem. Rev. Bras. Enferm. 2011;64(5):817-23.

21. Tavares FM. Reflexões acerca da latrogenia e Educação Médica. Rev. bras. educ. med. 2007;31(2):180-5.

22. Hadders-Algra M. Early diagnosis and early intervention in cerebral palsy. Front Neurol. 2014;24(5):185.

23. Waldow VR. Cuidar Expressão Humanizadora da Enfermagem. $1^{\text {a }}$ ed. Editora: Vozes; 2010.

24. Barbosa LBA; Motta ALC; Resck ZMR. Os paradigmas da modernidade e pós-modernidade e o processo de cuidar na enfermagem. Enfermería Global. 2015;14 (1):335-41. 